\title{
THE ROLE OF ABUSE IN THE DEVELOPMENT OF IRRITABLE BOWEL SYNDROME: A COMPARATIVE STUDY
}

\section{Ms G Eileen Rossouw}

M Sc (Counselling Psychology), RAU

Psychologist in Private Practice

\author{
Prof. Anita D Stuart \\ D Litt et Phil \\ Vice-Head of Psychology, Rand Afrikaans University
}

Corresponding author: adst@lw.rau.ac.za

\section{Prof. H Gertie Pretorius \\ D Litt et Phil \\ Professor of Psychology, Rand Afrikaans University}

Keywords: Functional Gastrointestinal disorders; Irritable Bowel Syndrome; sexual abuse; physical abuse and emotional abuse

\begin{abstract}
Irritable Bowel Syndrome (IBS) is defined as a chronic relapsing functional bowel disorder of unknown causes which is characterised by attacks of abdominal pain and change of bowel habit resulting in diarrhoea or constipation or both. The prevalence of IBS in the general population of Western countries is $14-24 \%$ of women and more commonly found in women than in men. Stress can exacerbate IBS and a significant association between IBS and sexual abuse and physical abuse in childhood and adulthood has been found in overseas studies. No such studies have however been conducted in South Africa. The role that abuse may play in the development of IBS forms the cornerstone of the present study. The participants consisted of 79 adult women aged over 20 years. They were grouped into four categories: abused women with IBS; abused women without IBS; non-abused women without IBS; and non-abused women with IBS. A statistical analysis was carried out to ascertain if there were any differences between the groups in terms of the sub-type of IBS, as well as the types of abuse suffered. The groups were also compared with regard to the levels of anger and anxiety experienced.
\end{abstract}

\section{OPSOMMING}

Prikkelbare Dermsindroom (PDS) word gedefinieer as 'n chroniese, herhalende, funksionele ingewandsversteuring wat gekenmerk word deur aanvalle van buikpyn en 'n verandering in ingewandsgewoontes, wat diarree of hardlywigheid, of beide, tot gevolg het. PDS kom voor by $14-24 \%$ van die vroulike populasie in Westerse lande en word meer by vroue as by mans aangetref. Volgens die verbandhoudende literatuur kan stres PDS vererger en 'n betekenisvolle verband is gevind tussen PDS en sowel seksuele as fisiese mishandeling in die kinderjare en volwassenheid. Die rol wat mishandeling kan speel in die ontwikkeling van PDS vorm die kern van die huidige studie. 'n Statistiese analise is gedoen om te bepaal of daar enige verskille tussen die groepe bestaan in terme van die subtipe van PDS wat voorkom, sowel as die tipes mishandeling wat ervaar is. Die groepe is ook vergelyk in terme van hulle vlakke van woede en angs. 


\section{INTRODUCTION}

Irritable Bowel Syndrome (IBS) is defined as a chronic relapsing functional large bowel disorder of unknown causes (Weber \& McCallum, 1992:1447). IBS is characterised by attacks of abdominal pain and change of bowel habit resulting in diarrhoea, constipation or both, where no structural alteration of the colon is found (Broome \& Llewelyn, 1995:170; Varis, 1987:135). These may be accompanied by bloating and mucous in the stools.

The causes of IBS are largely unknown, and there is no long lasting effective treatment. Irritable Bowel Syndrome is also known by terms such as "nervous stomach", "nervous colon syndrome", "spastic colon", or "spastic colitis". It is most probably the most common disorder encountered by gastroenterologists in the industrialised world (Farthing, 1995:171).

The symptoms appear to result from a dysfunction of the intestine and are therefore said to be "functional" (Heaton \& Thompson, 1999:155). The prevalence of IBS in the general population of Western countries is $14-24 \%$ of women, as IBS appears to be predominantly a women's syndrome. IBS represents one of the most common diagnoses made by Gastroenterologists (Talley, Fett \& Zinsmeister, 1995:367). It is maintained (Enck \& Wienbeck, 1993:980) that up to $70 \%$ of patients consulting a gastroenterologist suffer from Irritable Bowel Syndrome. This includes sub-types of pain predominant IBS, IBS with diarrhoea and/or constipation, as well as IBS with bloating. Despite all of this, physicians are still struggling to understand the pathogenesis of IBS.

The secret of success with IBS is to recognise it quickly and confidently. While the patient's gut is clearly malfunctioning, however, there is no test that may assist the doctor in making the diagnosis, nor current technology that can precisely measure the abnormality (Heaton \& Thompson, 1999:173). Once the diagnosis has been made it is of utmost importance that the sufferer is told, the syndrome explained and a good relationship then encouraged with a health-care giver. It becomes important to search for unspoken agendas in the life of the sufferer. Stress can exacerbate IBS, and sexual and physical abuse can pose complex problems that require the assistance of a skilled coun- sellor. These problems, if left, may lead to the intensified symptoms of IBS.

Women and children often bear the brunt of physical, emotional and sexual abuse. Abuse rates in women in America range from $20-76 \%$. There is no reason to believe that these figures would be different for South Africa. Abused women report a significantly higher number of medical problems and health-care system usage. Enck and Wienbeck (1993:979) report that a history of physical and sexual abuse during childhood or adulthood was found in up to $40 \%$ of patients with IBS and organic disorders. This is corroborated by Weber and McCallum (1992:1447), who are also of the opinion that effective history taking is the key to the diagnosis of IBS. The fact that up to one third of patients with IBS resort to alternative medicine (Drossman \& Thompson, 1992:1009) suggests that physicians may be failing to meet the needs of their patients. Because IBS symptoms are chronic or recurrent, patients should have a long-term relationship with a primary care provider who is able to read and evaluate the patient's verbal as well as non-verbal communication.

Leserman, Drossman, Li, Toomey, Nachman and Glogau (1996:4) point out that despite the high incidences of abuse in IBS sufferers, health care practitioners are unaware of their patients' histories of abuse. They found that physicians seeing these patients were aware of this abuse in only $17 \%$ of the abused women. Despite the high incidence of sexual and physical abuse these experiences tend to remain hidden from the treating practitioner, and as a result women are seldom referred for psychological counselling in order to help them address the consequences of their abuse. As such, the counselling psychologist and medical practitioners have the challenge of unravelling the mechanisms behind the symptoms, and to provide a rationale for therapy. The role that abuse may play in the development of IBS forms the cornerstone of the present study.

Gastroenterologists, general practitioners and patients with IBS are under no illusions that no universally effective treatment exists for the condition (Farthing, 1995:171). Since this syndrome is so common it may be tempting to consider it as a normal variant of daily living. However, for those suffering, this offers scant 
hope. An attempt needs to be made to understand IBS in its entirety, not to just treat it as a disease affecting only the body, but as one that affects the spirit of the sufferer as well. Thus, the whole person needs to be the focus of research and treatment if a greater understanding of IBS is to be gained.

\section{KEY CONCEPTS}

\section{Functional Gastrointestinal Disorders}

The symptoms of Functional Gastrointestinal Disorders appear to result from a dysfunction of the intestine and are therefore said to be "functional" (Heaton \& Thompson, 1999:167). There are no structural lesions causing the symptoms.

\section{Irritable Bowel Syndrome (IBS)}

Irritable Bowel Syndrome is defined as a chronic relapsing functional bowel disorder of unknown causes (Weber \& McCallum, 1992:1448). IBS is characterised by attacks of abdominal pain and change of bowel habit resulting in diarrhoea, constipation or both, where no structural alteration of the colon is found (Varis, $1987: 135)$. IBS is a constellation of symptoms, which consists of abdominal pain, altered bowel habit, and other symptoms such as abdominal bloating, a feeling of incomplete evacuation and mucous in the stools. The bowel habit is typically chaotic - intermittent constipation and diarrhoea, sometimes both in the same day.

\section{Sexual Abuse}

Sexual abuse usually takes the form of forcing the victim to take part in sexual activities against his/her will. This may also include the use of force, sadism or torture. Many forms of adult sexual abuse, even in married relationships, may be classified as rape or attempted rape. According to La Fontaine (1990:54) 'sexual abuse' refers to "bodily contact of all sorts: fondling, genital stimulation, oral and/or anal intercourse as well as vaginal intercourse". She remarks that some people may extend the meaning to include suggestive behaviour, sexual innuendo and exhibitionism.

When applied to children, this definition focuses on two main features: (i) it is an adult activity and it involves a child as victim, and (ii) the definitions of offender and victim depend on their ages and not on their relationship.

\section{Physical Abuse}

Wolfe (1999:104) defines physical abuse as "the infliction or endangerment of physical injury as a result of punching, beating, kicking, biting, burning, shaking or otherwise harming an individual". Thus, physical abuse is considered to be any deliberate physical assault on an individual's body that harms the recipient in any way. These injuries may be as a result of a single incident, or a pattern of injuries to a person that are non-accidental. It may, or may not, involve visible signs of injury. This type of abuse may include kicking, hitting, slapping, choking, burning, stabbing and shooting the victim.

\section{Emotional Abuse}

Emotional abuse is a type of abuse that is enacted at a purely emotional level such as verbal insults and emotional deprivation. It is considered to be any act associated with psychological, spiritual and other forms of abuse that relates to an individual's sense of integrity, freedom of expression and well-being (Hartman, 1995:72). Emotional abuse includes acts such as withholding affection, verbal attacks, constant belittling and controlling behaviour, as well as insulting behaviour, such as calling someone names such as 'stupid' or 'crazy'. It also includes threats to the victims, as well as to their family members, pets and belongings. Wolfe (1999:110) is of the opinion that emotional abuse exists to some degree in all forms of maltreatment, and thus the specific psychological consequences are poorly understood. Loring (1997:133) describes emotional abuse as continuous, but interspersed with some warmth and kindness.

\section{Trait and State Anxiety}

Trait anxiety refers to the relatively stable anxietyproneness, that is, the individual's tendency to respond to situations perceived as threatening with elevated state anxiety. Individuals who are high in trait anxiety tend to exhibit state anxiety elevations more often than do individuals low in trait anxiety, because they react to a wider range of situations as threatening or dangerous. Both state and trait anxiety form subscales of the State-Trait Anxiety Inventory (STAI).

\section{Trait and State Anger}

Trait anger is defined as "the disposition to perceive a wide range of situations as annoying or frustrating and the tendency to respond to such situations with more 
frequent elevations in state anger" (Spielberger, 1996:5). State anger is defined as "an emotional state marked by subjective feelings that vary in intensity from mild annoyance or irritation to intense fury and rage" (Spielberger, 1996:6). State and trait anger are subscales of the State-Trait Anger Expression Inventory (STAXI).

\section{RATIONALE FOR THE STUDY}

Functional bowel disease is strongly associated with women who have a history of past sexual and physical abuse (Weber \& McCallum, 1992:1448). In one of the first studies to document the high prevalence of sexual and physical abuse among female patients in a gastroenterology clinic, Drossman, Leserman, Nachman, Li, Gluck, Toomey and Mitchell (1990:829) administered a self-report questionnaire to 206 patients, where they found that $44 \%$ reported a history of sexual or physical trauma in childhood or later life. Since then a number of other studies have attempted to research this further.

In a study done by Walker, Katon, Roy-Byrne, Jemelka and Russo (1993:1502) patients with functional bowel disorders were found to be more likely to report histories of physical or sexual trauma than those patients with organic disorders. Furthermore, this study found that all of the patients who had experienced severe sexual trauma had IBS.

People have a body that accompanies them from the moment of birth until the moment of death. Everything that has happened to a person in his/her lifetime has also happened to his/her body. No matter the type of abuse, the body was there and affected by that abuse. Kritsberg and Miller-Kritsberg (1993:76) contend that this memory of abuse is etched into the survivor's body, and these memories may surface at any time, and usually quite unexpectedly, as headaches, nausea and other digestive problems, sexual dysfunction, pelvis pain or sudden fatigue. According to Levine (1991:94), memories can also trigger bodily sensations. History is an integral part of every person and as long as people think of the past as the source of all problems they, in a sense, set up an adversarial relationship within themselves. The belief that tragedies of the past cause later problems and render people vulnerable to future strain can become a self-fulfilling prophecy. It is often impos- sible to know for sure whether a given symptom/syndrome is, or is not, caused by a particular problem and it may be best to assume that there need not be any causal connection between two concomitant problems.

Only one population-based study has been reported (Talley, Fett, Zinsmeister \& Melton, 1994:1041). A selfreport questionnaire was mailed to a random sample of 919 people in Minnesota. Twenty-six percent of the population reported some form of abuse in the past, and $22 \%$ of this sample reported sexual abuse. When compared with a non-abused sample, those who had been sexually, emotionally or verbally abused as children or adults were 1,9 times more likely to develop a functional gastrointestinal disorder. Those who reported abuse in adulthood and childhood were about three times as likely to have IBS.

Some family cultures lack language for emotional experience (McDaniel, Hepworth \& Doherty, 1995:350). The adults may allow only language about physical experiences. Children in these families receive care for physical pain but not for emotional pain. This approach conditions children to experience any need or problem as physical, and physical symptoms become their language for a range of experiences. There may thus be a link between severe somatising behaviour and early deprivation, trauma, physical or sexual abuse.

The aforementioned research carried out in the United States of America displays a significant association between IBS and sexual and physical abuse in childhood and adulthood (Drossman et al. 1990:829; Talley et al. 1994:1041). However, related research regarding IBS and abuse in South Africa is alarmingly lacking and this leads to the question of whether a significant association between IBS and earlier sexual, emotional and physical abuse in women (the focus group for this study due to the higher prevalence of IBS found in women than in men) would be present in this country.

For the present study the following questions were asked:

- Do abused women and non-abused women with IBS suffer from different sub-types of IBS?

- Are there any differences in the types of abuse 
that IBS sufferers were subjected to when compared to abused subjects who had no IBS?

- Do abused versus non-abused IBS sufferers and abused versus non-abused non-IBS sufferers, differ from each other in terms of how anxious they feel and act, and in terms of how much anger they feel?

\section{AIM}

The present research forms part of a larger and broader research project initiated in 1996 by the Counselling and Research Centre for Psychogastroenterology of the Rand Afrikaans University in Johannesburg, South Africa. The emphasis of this project is on improving the understanding of the association between psychology and physiology, particularly as this is manifested in Irritable Bowel Syndrome. The project aimed to enable both the public and the medical profession gain a deeper understanding of IBS, and ultimately provide sufferers with an opportunity to develop more effective coping strategies in the management of IBS.

The present study aimed to assess the links between IBS and abuse. This was done by comparing four groups of women, making up a total of 79 participants. The four groups are:

- Group 1: Women who have been abused, and who suffer from IBS

- Group 2: Women who have been abused, and who do not suffer from IBS

- Group 3: Women who have not been abused, and who do not suffer from IBS

- Group 4: Women who have not been abused, and who do suffer from IBS.

Groups 1 and 4 were compared regarding the three sub-types of IBS, namely pain predominant IBS, IBS with diarrhoea and/or constipation, and IBS with bloating. Groups 1 and 2 were compared with regard to the various types of abuse, namely, physical, emotional and sexual abuse, as measured by the Abuse Questionnaire, a questionnaire devised for the purposes of this study (Rossouw, 1998). The four groups were also compared with regard to state-anxiety and trait anxiety; as well as state-anger, trait-anger, angry temperament, angry reaction, anger-in, anger-out and anger control.

The operationalised research aims were to ascertain:

- if there were statistically significant differences between Group 1 (abused women with IBS) and Group 4 (non-abused women with IBS) regarding the three sub-types of IBS (pain predominant IBS, IBS with diarrhoea/ constipation, IBS with bloating) measured by means of the Irritable Bowel Syndrome Checklist;

- if there were statistically significant differences between Group 1 (abused women with IBS) versus Group 2 (abused women without IBS) regarding the three types of Abuse (emotional abuse, physical abuse, sexual abuse) measured by means of the Abuse Questionnaire (Rossouw, 1998); and

- if there were statistically significant differences between Group 1 (abused women with IBS) versus Group 2 (abused women without IBS) and Group 3 (non-abused women without IBS) versus Group 4 (non-abused women with IBS) regarding anxiety and anger as measured by means of the nine subscales of the State-Trait Anxiety Inventory (STAI) and the State-Trait Anger Expression Inventory (STAXI).

\section{RESEARCH METHOD}

Only adult women (above 20 years of age) were recruited for this study, due to IBS being commonly found in adult women. Women attending a conference for women, Radiography students at the Technikon Witwatersrand in Johannesburg and clients seeing the Intern Psychologist at the Centre for Peace Action (Eldorado Park, Johannesburg) were requested to fill in the questionnaires, consisting of the following:

- Biographical Questionnaire

- Abuse Questionnaire

- Irritable Bowel Syndrome Checklist

- State-Trait Anxiety Inventory (Spielberger, 1983

- State-Trait Anger Expression Inventory (Spielberger, 1996).

Every woman who correctly completed the full questionnaire was eligible for one of the four groups. 
The women in the study ranged in age from 20-70 years, and the demographic characteristics were as follows:

- 46 white, 13 black, and 20 coloured and Indian

- 43 married, 27 single and 9 divorced/widowed.

- 17 had a secondary school education, 48 had completed Matric and 14 had post-Matric qualifications

- 55 were employed and 24 were not employed.

Of all the subjects tested, $68 \%$ had suffered some form of abuse. More than half (59\%) of all the subjects suffered from IBS. Thirty-eight percent of the subjects had been abused and suffered from IBS. Fifteen percent of the subjects suffered from IBS although they had not been previously abused. The questionnaires were coded and from the responses on the Abuse Questionnaire and the Irritable Bowel Syndrome Checklist 79 participants out of the 85 , returned questionnaires, were allocated to one of the following groups:

- Group 1: Abused women with IBS $(n=30)$

- Group 2: Abused women without IBS ( $n=24)$

- Group 3: Non-abused women without IBS ( $n=13)$

- Group 4: Non-abused women with IBS ( $n=12)$.

Groups 1 and 4 were compared regarding the three sub-types of IBS, namely, pain predominant IBS, IBS with diarrhoea and/or constipation, and IBS with bloating. Based on the study done by Leroi (in Drossman, Talley, Leserman, Olden \& Barreiro, 1995:783), where it was found that the frequency of sexual abuse was found to be greater in those patients with lower functional gastrointestinal disorders than those with upper gastrointestinal disorders, it was hypothesised that those women who had been abused would be more likely to suffer from pain predominant IBS, and IBS with diarrhoea and/or constipation, than IBS with bloating.

Groups 1 and 2 were compared with regard to the various types of abuse, namely emotional, physical and sexual abuse, as measured by the Abuse Questionnaire. In a study carried out by Talley, Kramlinger, Burton, Colwell and Zinsmeister (1993:648), 32 married patients (both male and female) with IBS were evaluated, using their healthy spouses as controls. It was found that although abuse was reported more frequently in IBS sufferers than in the controls, it could not be confirmed that a relationship existed between childhood sexual abuse and IBS. Thus contradicting many of the previous studies cited (Drossman et al. 1990:829; Drossman et al. 1995:783; Felitti, 1991:329; Talley et al. 1994:1042; Walker et al. 1993:1502; Walker \& Katon, 1996:16), where the rates of physical and sexual abuse were found to be high in patients suffering from IBS. Not much research has been carried out into the rates and effects of emotional abuse, thus, the researcher sought to include this factor into the research.

The four groups were also compared with regard to state-anxiety and trait anxiety; as well as state-anger, trait-anger, angry temperament, angry reaction, angerin, anger-out and anger control. A number of studies have reported that women suffering from IBS have high rates of anxiety (Briere \& Runtz, 1988:51; Lowman, Drossman, Cramer, \& McKee, 1987:325; Walker, Katon, Hansom, Harrop-Griffiths, Holm, Jones, Hickok, \& Jemelka, 1992:659), thus the present research sought to measure this. Nyhlin, Ford, Eastwood, Smith, Nicol, Elton and Eastwood (1993:155) found that IBS patients have more difficulty expressing negative feelings towards others than did the control group, thus the researcher also hypothesised that women who had been abused might have feelings of unresolved anger that may affect their health.

\section{RESULTS}

Pearson's Chi-square test was carried out to ascertain if there were any significant differences between Group 1 (abused women with IBS) and Group 4 (non-abused women with IBS) regarding the sub-types of IBS, namely pain predominant IBS, diarrhoea/constipation predominant IBS and bloating predominant IBS. Manova and Anova tests were carried out for differences between Group 1 (abused women with IBS) and Group 2 (abused women without IBS) regarding the three abuse subscales, namely emotional abuse, physical abuse and sexual abuse. Manova, Anova and Scheffe tests were carried out to ascertain if there were any significant differences between Group 1 (abused women with IBS), Group 2 (abused women without IBS), Group 3 (non-abused women without IBS) and Group 4 (nonabused women with IBS) regarding the two anxiety sub- 
scales and the seven anger sub-scales.

Below is a summary of the most important results obtained from the various questionnaires.

- Fifty-four (68\%) of the women in the study had suffered some form of abuse. Of these women, the most prevalent abuse was physical abuse (89\%), with rates of emotional abuse also being very high $(87 \%)$, and $63 \%$ of women having suffered from sexual abuse.

- Women who had been abused (Group 1 and Group 2), whether they suffered from IBS or not, were more likely to also suffer from somatic symptoms than those who had not been abused.

- Of those women who had been abused and who had IBS, the highest percentage suffered from IBS with bloating (43\%), 37\% suffered from IBS with pain, and $20 \%$ suffered from IBS with diarrhoea and/or constipation.

- Half of the women (50\%) who had not been abused but who suffered from IBS, suffered from IBS with pain.

\section{DISCUSSION}

No statistically significant differences were found between Groups 1 and 4 in terms of IBS subtypes as seen in Table 1.

This means that earlier research which holds that patients who suffered sexual abuse would be more likely to suffer pain-predominant or diarrhoea/constipation type IBS may not always hold true. This suggests that enquiries about a history of abuse is always valuable no matter what sub-type of IBS a women suffers from.

Groups 1 and 2 were compared with regard to the various types of abuse, namely physical, emotional and sexual abuse, as measured by the Abuse Questionnaire as seen in Table 2.
Table 1: Significance of differences between Group 1 (abused women with IBS) and Group 4 (non-abused women with IBS) regarding Type of IBS

\begin{tabular}{|l|l|}
\hline DF & 2 \\
\hline Pearson Chi-Square & 1.233 \\
\hline P value & 0.540 \\
\hline
\end{tabular}

Table 2: Significance of differences between Group 1 (abused women with IBS) and Group 2 (abused women without IBS) regarding the three types of abuse taken separately

\begin{tabular}{|c|c|c|c|c|c|}
\hline Group & $\begin{array}{l}\text { Dep } \\
\text { variable }\end{array}$ & $\begin{array}{l}\text { Type III Sum } \\
\text { of Squares }\end{array}$ & DF & $\mathbf{F}$ & Sig. \\
\hline & Emotional & 1.134 & 1 & 0.003 & 0.954 \\
\hline & Physical & 52.448 & 1 & 0.422 & 0.519 \\
\hline 1 vs 2 & $\begin{array}{l}\text { Sexual } \\
\text { abuse }\end{array}$ & 7.668 & 1 & 0.072 & 0.789 \\
\hline
\end{tabular}

No statistically significant differences were found between Groups 1 and 2 in terms of the types of abuse. According to this finding, any type of abuse may be a predisposing factor for the later occurrence of IBS, and not only physical and sexual abuse as reported by the other studies cited.

The four groups were also compared with regard to state-anxiety and trait anxiety; as well as state-anger, trait-anger, angry temperament, angry reaction, angerin, anger-out and anger control as seen in Table 3.

Once again no statistically significant differences were found between these groups because the Wilks' Lambda is not statistically significant. This indicates that women are mostly silent in their suffering.

The present study found high rates of abuse in the general population with $68 \%$ of the sample reporting abuse. Of these abused women, $38 \%$ could be diagnosed with IBS. Fifteen percent of the sample were women who had not been abused but who did have IBS. It can be deduced that, the presence of abuse predisposes a woman for IBS. 
Table 3: Significance of differences between Group 1 (abused women with IBS) versus Group 2 (abused women without IBS) versus Group 3 (non-abused women without IBS) versus Group 4 (non-abused women with IBS) regarding anxiety, trait anxiety, state anger, trait anger, angry temperament, angry reaction, anger-in, anger-out and anger control taken separately according to Wilks' Lambda

\begin{tabular}{|c|c|c|c|c|c|c|}
\hline Group & Dep variable & $\begin{array}{l}\text { Sum of } \\
\text { Square }\end{array}$ & DF & $\begin{array}{l}\text { Mean } \\
\text { Square }\end{array}$ & $F$ & Sig. \\
\hline Between groups & \multirow[t]{3}{*}{ State-Anxiety } & 752.786 & 3 & 250.929 & 2.024 & 0.118 \\
\hline Within groups & & 9300.049 & 75 & 124.001 & & \\
\hline Total & & 10052.8 & 78 & & & \\
\hline Between groups & \multirow[t]{3}{*}{ Trait-Anxiety } & 1393.192 & 3 & 464.397 & 3.446 & 0.021 \\
\hline Within groups & & 10108.1 & 75 & 134.775 & & \\
\hline Total & & 11501.3 & 78 & & & \\
\hline Between groups & \multirow[t]{3}{*}{ State-Anger } & 272.236 & 3 & 90.745 & 2.331 & 0.081 \\
\hline Within groups & & 2920.194 & 75 & 38.936 & & \\
\hline Total & & 3192.43 & 78 & & & \\
\hline Between groups & \multirow[t]{3}{*}{ Trait-Anger } & 306.662 & 3 & 102.221 & 3.08 & 0.032 \\
\hline Within groups & & 2488.883 & 75 & 33.185 & & \\
\hline Total & & 2795.544 & 78 & & & \\
\hline Between groups & \multirow{3}{*}{$\begin{array}{l}\text { Angry } \\
\text { Temperament }\end{array}$} & 70.808 & 3 & 23.603 & 2.901 & 0.040 \\
\hline Within groups & & 610.281 & 75 & 8.137 & & \\
\hline Total & & 681.089 & 78 & & & \\
\hline Between groups & \multirow{3}{*}{$\begin{array}{l}\text { Angry } \\
\text { Reaction }\end{array}$} & 49.988 & 3 & 16.663 & 2.034 & 0.116 \\
\hline Within groups & & 614.316 & 75 & 8.191 & & \\
\hline Total & & 664.304 & 78 & & & \\
\hline Between groups & \multirow[t]{3}{*}{ Anger-in } & 50.36 & 3 & 16.787 & 0.813 & 0.491 \\
\hline Within groups & & 1548.349 & 75 & 20.645 & & \\
\hline Total & & 1598.709 & 78 & & & \\
\hline Between groups & \multirow[t]{3}{*}{ Anger-out } & 114.616 & 3 & 38.205 & 1.92 & 0.134 \\
\hline Within groups & & 1492.473 & 75 & 19.9 & & \\
\hline Total & & 1607.089 & 78 & & & \\
\hline Between groups & \multirow[t]{3}{*}{ Anger control } & 76.017 & 3 & 25.339 & 1.178 & 0.324 \\
\hline Within groups & & 1613.528 & 75 & 21.514 & & \\
\hline Total & & 1689.544 & 78 & & & \\
\hline
\end{tabular}

In contrast to the studies carried out by Drossman et al. (1990:829); Talley et al. (1994:1041) as well as Walker and Katon (1996:17), who found the presence of sexual and/or physical abuse in those women who suffered from IBS, the present study found that there were no statistically significant differences between Group 1 (abused women with IBS) and Group 2 (abused women without IBS) in terms of the types of abuse. It can thus be postulated that women with IBS may have been victims of emotional and verbal abuse, just as they may have been victims of sexual or physical abuse. This finding has implications for medical practitioners and the type of questions they should be posing in order to aid any IBS sufferer.

Heaton and Thompson (1999:81) are of the opinion that 
there is therapeutic value in a good relationship with an empathic healthcare provider. They state that the ultimate goal of this relationship should be to empower the patient; in particular the patients who perceive their symptoms as no more than a nuisance, as well as the silent majority of people with IBS who do not seek healthcare.

Only one study, by Leroi (in Drossman et al. 1995:783), has compared abuse frequencies with different functional gastrointestinal disorders. This researcher found that the frequency of sexual abuse was greater in clinic patients with functional lower gastrointestinal tract disorders than in those with functional upper gastrointestinal tract disorders. Abused patients were more likely than non-abused patients to report constipation, diarrhoea or pelvic floor dyssynergia (obstructive defecation). These findings are not in line with those of the present study, which has found that no statistically significant differences have been found to exist between Group 1 (abused women with IBS) and Group 4 (non-abused women with IBS) in terms of the sub-types of IBS. Thus it would seem that it is not possible to determine what type of abuse a woman had suffered on the strength of the sub-type of IBS. In fact the present study found that, of those women who had been abused and who had IBS, the highest percentage suffered from IBS with bloating (43\%) which may be considered a functional upper gastrointestinal tract disorder. Of the women suffering from IBS who had experienced abuse $37 \%$ suffered from IBS with pain, and $20 \%$ suffered from IBS with diarrhoea and/or constipation.

In a study cited by Greenwald, Leitenberg, Cado and Tarran (1990:503) a random sample of adult women were compared with those who had been abused either in childhood or in adolescence. It was found that those who had been abused as children differed from the controls in the anxiety subscale of the Derogatis Symptom Checklist. Research carried out by Wilson (1997:55) found that $81,3 \%$ of IBS patients studied, reported elevated levels of generalised anxiety, with $46,2 \%$ of these manifesting clinically significant levels. These studies do not confirm the findings of the present study which has shown that no statistically significant differences exist between Group 1 (abused women with IBS) versus Group 2 (abused women without IBS), and Group 3 (non-abused women without IBS) versus Group 4 (non-abused women with IBS) in terms of the sub-scales of the STAXI and the STAI. However, a visual scanning of the means of the various Groups (Table 1) are of interest. The higher scores in state anxiety and trait anxiety, in all the groups of women who had been abused (that is Group 1 and Group 2), should be noted. The scores for state anger and trait anger are also elevated for those groups of women who had been abused, relative to those who had not been abused. It can also be observed that those women who had been abused and who suffer from IBS, had relatively higher scores of trait anxiety and trait anger, than those who suffered from IBS but who had not been abused. These findings are in line with those of Nyhlin et al. (1993:155) who are of the opinion that IBS is but one facet of a more general condition and a separate pattern of illness behaviour that is characterised by an unassertiveness in expressing personal feelings. It appears that these women may be anxious or angry but may be unable to express these feelings in a healthy way and instead internalise these conflicts thus becoming anger-prone or anxietyprone. This continual bottling up of powerful emotions could feasibly lead to the development of IBS.

\section{CONCLUSION}

The present study has sought to investigate the association between IBS and abuse from a number of diverse angles. It provides a number of answers and it leads to a fuller understanding of the links between IBS and abuse in the South African context. It highlights one of the possible effects of emotional abuse, and the need to investigate this type of abuse as well as physical and sexual abuse when recording a medical history. At the same time it challenges various earlier research findings.

This study highlights a number of factors not recognised in other studies. Lechner, Vogel, GarciaShelton, Leichter and Steibel (1993:634) state that the association between self-perceived multiple illnesses, vague medical complaints and a history of childhood sexual abuse are often not understood even by the individual. Many women keep their experiences of abuse private but tactful enquiries provide the physician with an opportunity to explore and identify the problem. 
It might be that every person has his/her own IBS story, and that every person tells that story in the way that is right for him/her. Searching for a general finding that is applicable to all, may prove to be futile. If every IBS sufferer is treated as an individual, with a body that has its own poetics of illness, then this syndrome may move closer to being solvable. It is trusted that the study has made some small contribution to the understanding of IBS in abused women and the interaction between this abuse and IBS.

\section{REFERENCES}

BRIERE, J \& RUNTZ, M 1988: Symptomatology associated with childhood sexual victimization in a nonclinical adult sample. Child Abuse and Neglect, 12:51-59.

BROOME, A \& LLEWELYN, S 1995: Health psychology: Processes and applications. London: Chapman \& Hall.

DROSSMAN, D; LESERMAN, J; NACHMAN, G; LI, Z; GLUCK, H; TOOMEY, T \& MITCHELL, CM 1990: Sexual and physical abuse in women with functional or organic gastrointestinal disorders. Annals of Internal Medicine, 113:828-833.

DROSSMAN, D; TALLEY, N; LESERMAN, J; OLDEN, K \& BARREIRO, MA 1995: Sexual and physical abuse and gastrointestinal illness: Review and recommendations. Annals of Internal Medicine, 123:782-794.

DROSSMAN, D \& THOMPSON, WG 1992: The Irritable Bowel Syndrome: Review and a graduated multicomponent treatment approach. Annals of Internal Medicine, 116:1009-1016.

ENCK, P \& WIENBECK, M 1993: Epidemiology and psychological factors of the Irritable Bowel Syndrome. European Journal of Gastroenterology and Hepatology, 5(12):979-989.

FARTHING, MJG 1995: Irritable bowel, irritable body, or irritable brain? British Medical Journal, 310:171-175.

FELITTI, V 1991: Long-term consequences of incest, rape and molestation. South African Medical Journal, 84:328-331.

GREENWALD, E; LEITENBERG, H; CADO, S \& TARRAN, MJ 1990: Childhood sexual abuse: Long-term effects on psychological and sexual functioning in a nonclinical and nonstudent sample of adult women. Child Abuse \& Neglect, 14:503-513.

HARTMAN, W 1995: Ego state therapy with sexually traumatized children. Pretoria: Kagiso.

HEATON, KW \& THOMPSON, WG 1999: Fast facts - Irritable Bowel Syndrome. Oxford: Health Press.

KRITSBERG, W \& MILLER-KRITSBERG, C 1993: The invisible wound: A new approach to healing childhood sexual abuse. New York: Bantam Books.

LA FONTAINE, J 1990: Child sexual abuse. Cambridge: Polity.

LECHNER, ME; VOGEL, ME; GARCIA-SHELTON, LM; LEICHTER, JL
\& STEIBEL, KR 1993: Self-reported medical problems of adult female survivors of childhood sexual abuse. The Journal of Family Practice, 36:633-638.

LESERMAN, J; DROSSMAN, D; LI, Z; TOOMEY, TC; NACHMAN, G \& GLOGAU, L 1996: Sexual and physical abuse history in gastroenterology practice: How types of abuse impact health status. Psychosomatic Medicine, 58:4-15.

LEVINE, B 1991: Your body believes every word you say. Los Angeles: Aslan.

LORING, M 1997: Stories from the heart: Case studies of emotional abuse. Amsterdam: Harwood.

LOWMAN, B; DROSSMAN, D; CRAMER, E \& MCKEE, D 1987: Recollection of childhood events in adults with Irritable Bowel Syndrome. Journal of Clinical Gastroenterology, 9:3, 324-330. MCDANIEL, S; HEPWORTH, J \& DOHERTY, W 1995: Medical family therapy with somaticizing patients: The co-creation of therapeutic stories. Family Process, 34:349-361.

NYHLIN, H; FORD, MJ; EASTWOOD, J; SMITH, JH; NICOL, EF; ELTON, RA \& EASTWOOD, MA 1993: Non-alimentary aspects of the Irritable Bowel Syndrome. Journal of Psychosomatic Research, 37(2):155-162.

ROSSOUW, GE 1998: Abuse questionnaire. Unpublished questionnaire for the purposes of this dissertation.

SPIELBERGER, C 1983: State-trait anxiety inventory for adults. Palo Alto: Mind Garden.

SPIELBERGER, C 1996: State-trait anger expression inventory. Odessa: Psychological Assessment Resources.

TALLEY, NJ; FETT, SL \& ZINSMEISTER, AR 1995: Self-reported abuse and gastrointestinal disease in outpatients: Association with Irritable Bowel-Type symptoms. American Journal of Gastroenterology, 90:366-371.

TALLEY, N; FETT, S; ZINSMEISTER, A \& MELTON, L 1994: Gastrointestinal tract symptoms and self-reported abuse: $A$ population-based study. American Gastroenterological Association, 1:1040-1049.

TALLEY, N; KRAMLINGER, KG; BURTON, MC; COLWELL, LJ \& ZINSMEISTER, AR 1993: Psychiatric disorders and childhood abuse in the Irritable Bowel Syndrome. European Journal of Gastroenterology \& Hepatology, 5:647-654.

VARIS, K 1987: Psychosomatic factors in gastrointestinal disorders. Annals of Clinical Research, 19:135-142.

WALKER, E \& KATON, W 1996: Researching the health effects of victimization: The next generation. Psychosomatic Medicine, 58:1617.

WALKER, E; KATON, W; HANSOM, J; HARROP-GRIFFITHS, J; HOLM, L; JONES, M; HICKOK, L \& JEMELKA, R 1992: Medical and psychiatric symptoms in women with childhood sexual abuse. Psychosomatic Medicine, 54:658-664.

WALKER, EA; KATON, W; ROY-BYRNE, PP; JEMELKA, RP \& 
RUSSO, J 1993: Histories of sexual victimization in patients with Irritable Bowel Syndrome or inflammatory bowel disease. American Journal of Psychiatry, 150(10):1502-1506.

WEBER, FH \& MCCALLUM, R 1992: Clinical approaches to Irritable Bowel Syndrome. Lancet, 340(12):1447-1452.

WILSON, M 1997: The incidence of concurrent psychopathology in patients suffering from Irritable Bowel Syndrome. Johannesburg: Rand Afrikaans University.

WOLFE, D 1999: Child abuse: Implications for child development and psychopathology. Thousand Oaks: Sage. 